\title{
Cooperativas Escolares como una forma de fomentar la capacidad emprendedora asociativa de niños y jóvenes ${ }^{1}$
}

\author{
Mario Radrigán ${ }^{2}$; ; Ana María Dávila Rodríguez ${ }^{3}$ y Julián Bellei Tobar ${ }^{4}\left({ }^{\circ}\right.$
}

Recibido: 17 de diciembre de 2018 / Aceptado: 9 de marzo de 2020 / Publicado: 14 de octubre de 2020

Resumen. El presente artículo corresponde a la sistematización de una experiencia histórica de casi 20 años de promoción del modelo de cooperativas escolares en Chile, que se inicia el año 1998 con apoyo de la Cooperativa de Ahorro y Crédito COOPEUCH, y que inicialmente fue promovida por el Programa Interdisciplinario de Estudios Asociativos, PROASOCIA, de la Universidad de Chile y posteriormente por el Centro Internacional de Economía Social de la Universidad de Santiago de Chile, que ha tenido siempre el propósito el acercar el modelo empresarial cooperativo a las nuevas generaciones que están inmersas en el medio escolar, y que de esta forma pueden experimentar de forma directa y práctica una iniciativa emprendedora de orientación social.

Este artículo presenta la primera sistematización longitudinal que se realiza de esta iniciativa y que además reflexiona sobre los distintas dimensiones críticas que dicen relación con este tipo de experiencias, como son por ejemplo la edad de los participantes, el nivel de involucramiento de los directivos de los centros escolares, la relación con el currículum escolar y las percepciones que los propios estudiantes tienen de sus propias iniciativas, generando con ellos recomendaciones para el impulso de los procesos de promoción del emprendimiento a nivel escolar.

Palabras clave: Emprendimiento; Currículum Escolar; Cooperativismo; Escuela; Juventud; Niñez.

Claves Econlit: J54; L26; L31; P13.

\section{[en] School cooperatives as a way to promote the associative entrepreneurial capacity of children and youth}

\begin{abstract}
This article corresponds to the systematization of a historical experience of almost 20 years of promotion of the model of school cooperatives in Chile, which began in 1998 with the support of the Cooperativa de Ahorro y Crédito COOPEUCH, and which was initially promoted by the Program Interdisciplinary of Associative Studies, PROASOCIA, of the University of Chile and later by the International Social Economy Center of the University of Santiago de Chile, which has always had the purpose of bringing the cooperative business model to the new generations that are immersed in the school environment, and that in this way they can experience directly and practically a socially oriented entrepreneurial initiative. This article presents the first longitudinal systematization that is carried out of this initiative and that also reflects on the different critical dimensions that relate to this type of experiences, such as, for example, the age of the participants, the level of involvement of the directors of the schools, the relation with the school curriculum and the perceptions that the own students have of their own initiatives, generating with them recommendations for the impulse of the processes of promotion of the emprendimiento at scholastic level.
\end{abstract}

Keywords: Entrepreneurship; School curriculum; Cooperativism; School; Youth; Childhood.

Sumario. 1. Introducción. 2. Metodología. 3. Resultados. 4. Conclusiones y recomendaciones finales. 5. Referencias bibliográficas.

Cómo citar. Radrigán, M.; Dávila Rodríguez, A.M.; Bellei Tobar, J. (2020) Cooperativas Escolares como una forma de fomentar la capacidad emprendedora asociativa de niños y jóvenes. REVESCO. Revista de Estudios Cooperativos, vol. 136 , e69188. https://dx.doi.org/10.5209/reve.69188.

1 Se deja constancia que el presente artículo ha contado con el apoyo del Fondo VRIDEI-DICYT que ha financiado el proyecto código $\mathrm{N}^{\circ}$ 0031364RR, lo cual se agradece.

2 Universidad de Santiago de Chile, Chile.

Dirección de correo electrónico: mario.radrigan@usach.cl.

3 Universidad de Santiago de Chile, Chile.

Dirección de correo electrónico: anamaria.davila@usach.cl.

4 Universidad de Santiago de Chile, Chile.

Dirección de correo electrónico: julian.bellei@usach.cl. 


\section{Introducción}

En los últimos 20 años a nivel global, el tema del emprendimiento y del emprendedor, ha ido adquiriendo cada vez más importancia tanto para los gobiernos, como para las entidades empresariales y para el mismo mundo de la vida escolar, pero aún falta mucho camino por recorrer (Radrigán, 2007). Desde el punto de vista de los desafíos país en el desarrollo del Emprendimiento, el informe de Global Entrepreneurship Monitor Chile (GEM, 2012), señala que la mayoría de las personas prefieren ser empleadas antes que emprender y en general no se promueve la iniciativa y autonomía personal, fomentando escasamente la creatividad y la innovación. (ver también Morales \& Ariza 2013:28)

En el estudio "Línea base de cultura de innovación en la sociedad chilena" (Consejo Nacional de Innovación para la Competitividad, 2008) se detectan variables claves en la generación de prácticas innovadoras tales como la curiosidad, colaboración, confianza, propensión al riesgo y aceptación del fracaso, no se encuentran suficientemente estimuladas por el entorno socioeducativo chileno. De igual forma, en el Estudio Base Innovación de Corporación de Fomento del Gobierno de Chile (CORFO, 2013), se advierte que aún no se desarrolla con fuerza el principio de la "colaboración" para innovar y de "confianza" en "los demás o en sí mismo", o de "tolerar el fracaso". Reflejando entonces algunos de los desafíos en materia de educación para el emprendimiento, los cuales deberían ser abordados desde la oferta curricular en todo el ciclo educativo.

También la crisis del trabajo abordado en la tesis de Rodríguez (2004), indica que el sujeto trabajador ha perdido su carácter de constructor social, de ente creativo e imprescindible, para pasar a ser fuerza de trabajo sólo en su dimensión de mercancía; dejando entonces la puerta abierta a nuevas prácticas en el aula de clases, que fomente la capacidad emprendedora asociativa en niños y jóvenes.

Incluso el Grupo de Expertos convocados por la Comisión Europea para hacer un diagnóstico de la cuestión (Comisión Europea, 2002:7), señala entre sus conclusiones la descoordinación entre los diversos actores del sistema, iniciativas impulsadas externamente y la falta de integración real al curriculum escolar. (ver también Moreno: 2000). A nivel nacional este diagnóstico es compartido por Ahumada (2017) en cuya tesis afirma que el curriculum escolar está orientado hacia una salida laboral dependiente, asegurando además que, el entrenamiento necesario para desarrollar la habilidad emprendedora no es incorporado en ningún aspecto del currículo escolar y a partir de esta necesidad nacen como respuesta el movimiento de cooperativas escolares.

En su artículo de investigación, Radrigán (2007) afirma que, en otros países, las cooperativas escolares se desarrollan a través de políticas públicas con apoyo de distintas instituciones, dando a conocer el caso español "Valnalón Ciudad Tecnológica", esta experiencia cuenta con el apoyo del Gobierno del Principado de Asturias a través del Programa de Fomento de la Cultura Emprendedora de dicho país, permitiendo el desarrollo de diversas iniciativas a nivel educativo. También en este texto se presenta el caso francés, donde la Oficina Central de la Cooperación en la Escuela (OCCE) tiene presencia en el apoyo a las cooperativas escolares en todo el país. El caso más reciente es el italiano, donde existe la Confederación de Cooperativas de Italia, organización que permite a las cooperativas escolares federarse.

En Chile funcionaron alrededor de 81 cooperativas escolares desde 1998, 28 de estas se encontraban en la Región Metropolitana, en la actualidad cuatro se encuentran activas y entregaron información relevante sobre los estudiantes.

\subsection{Antecedentes de la estructura educacional en Chile}

Según la Ley General de Educación del año 2009, en Chile existen cuatro fases en la educación: Parvularia, básica, media y superior. Este trabajo se enfocará en la educación básica y media (donde frecuentan las cooperativas escolares). A continuación, se detallarán sus antecedentes y transformaciones.

En la época colonial, la educación estuvo a cargo de la Iglesia Católica (Jesuitas y Domínicos), con financiamiento eclesiástico y posteriormente con la independencia, la educación se transforma en un tema de interés nacional, creándose el Instituto Nacional y la Universidad de Chile (sucesora de la Universidad de San Felipe), pasando a tener una estructura de financiamiento con cargo al Estado de Chile. Luego se crea la Escuela de Artes y Oficios (EAO) para el desarrollo de la educación técnica y para responder a las necesidades de industrialización del país, mediante la capacitación técnica. En 1877 se incorpora la mujer a la educación superior con el decreto del ministro de Educación, Miguel Luis Amunategui con el fin de incluirlas considerando sus capacidades (hasta entonces no tomadas en cuenta por la sociedad de la época). (Mancilla; 2005)

Durante el siglo XIX la convivencia entre las instituciones de educación públicas (Estado) y privadas (Iglesia) fue sana, debido a que no tenían intereses contrapuestos, sin embargo, las diferencias comenzaron presentarse con la llegada de la República Liberal, por una parte la fiscalización estatal sobre la educación y por otra, la libertad de enseñanza provocaron "cuestiones teológicas", debates sobre la injerencia del Estado en la educación, marcándose así una clara diferencia entre lo público y lo privado que finalizó con la 
fundación de la Universidad Católica de Chile (primer centro privado de estudios superiores en Chile) en 1888 y el Instituto Pedagógico por parte del Estado.

La creación de diversas universidades tanto públicas como privadas a lo largo del país se efectuó en el siglo XX, caracterizadas por expandir la libertad de enseñanza o culto con la proliferación de universidades católicas y por expandir la presencia del Estado en Regiones (Universidad Técnica del Estado y Universidad de Chile); dejando en evidencia diferencias educacionales plasmadas en las mallas curriculares de las carreras a cursar.

El Golpe de Estado ocurrió en 1973, generando un proceso de cambios ideológicos, políticos, económicos, sociales y estructurales que promovieron la privatización de la educación, un retroceso democrático (prohibición de partidos políticos, libertades y DDHH), la fragmentación de universidades estatales y una proliferación de universidades privadas que nunca antes se había dado. Se estableció entonces una lógica de mercado en el sistema educacional pasando a considerarse un "bien de consumo" y no un derecho. Estableciendo que el acceso a la educación depende de la capacidad económica del estudiante y su familia (Redondo, 2015)

El retorno de la democracia (1989-1990) se caracterizó por una serie de cambios curriculares en la educación, un aumento en el acceso y la calidad de los establecimientos, también se establece el Estatuto Docente que norma los requisitos, deberes obligaciones y derechos de los profesores. Algunas medidas tomadas durante el periodo dictatorial de Augusto Pinochet continuaron, como la administración de los establecimientos estatales de enseñanza media que siguieron a cargo de los Municipios, el alza en los aranceles universitarios y la proliferación de colegios y universidades privadas orientadas a estudiantes de familias con mayores ingresos. (Cruz-Coke, R; 2004).

Con el alza de aranceles también se crearon sistemas de becas y créditos para garantizar el acceso a la educación superior, sin embargo, en la actualidad estas herramientas han sido altamente cuestionadas por el grado de endeudamiento del estudiante al egresar. Este descontento social por los aranceles (mensualidades) para poder acceder a los estudios superiores y la relación "precio-calidad" en materias educacionales, hizo perder el sentido de una educación "para todos" con acceso y equidad. Entre el 2006 y el 2011 se realizaron una serie de manifestaciones protagonizadas por los estudiantes, con el objetivo de exigir gratuidad y calidad en la educación, debido a que la educación universitaria en Chile es una de las más costosas del mundo según la OCDE (Publimetro, 2013).

En el año 2016 comenzó a regir la gratuidad universitaria de manera gradual, comenzando por el 50\% de los estudiantes más vulnerables del país y solo para aquellos estudiantes que ingresen a las universidades del Consejo de Rectores de Universidades Chilenas (CRUCH) y a las universidades privadas suscritas.

\subsection{Economía Social y Cooperativa}

La socióloga Andrea Levin, enfatiza en su trabajo "Teoría e Historia de la Economía Social" (2015), que fue en Europa en la primera mitad del siglo XIX donde comenzaron a originarse instituciones semejantes a las organizaciones de la economía social, teniendo como antecedentes a las cofradías, guildas y trabajos sociales ligados a la religión. Para Levin, es posible encontrar escritos desde el siglo XV donde se visualizan organizaciones sin vicios de la época, haciendo un hincapié en la posibilidad de lograr organizaciones sociales basadas en los valores religiosos, destacándose en esta época a Tomás Moro con su trabajo "Utopía", donde sueña con un Estado ideal, con solidaridad entre su población y con la caridad de ser "buenos cristianos", esto permitió abrir la "utopía social", tema donde comenzaron a escribir autores como Bacon y Campanella, contando sus propias utopías de una sociedad moderna con características de cooperación entre sus habitantes.

Siguiendo con la explicación de la socióloga, Peter Cornelius Plockboy, un holandés radicado en Inglaterra fue el creador de la antesala de la actividad cooperativa, al acercarse a los "cuáqueros", pues sus trabajos religiosos funcionaban de forma cooperativa, con ayuda mutua y de interpretación alternativa al cristianismo oficial. Los cuáqueros fueron generando una conciencia social arraigada en los países donde prosperaron sus ideas, justificándose por ejemplo en la economía colectiva (esencialmente en la agricultura), potenciando la baja de precios por la producción mancomunada y también por el gran abastecimiento o suministro que generaba el trabajo cooperativo.

Radrigán (2007) afirma que la Economía Social es un sector de la economía que presenta ciertos caracteres homogéneos que la diferencian por su fin y por su estructura de otros sectores como son el público o el capitalista. Este sector también es conocido como el Tercer Sector, Economía Solidaria, Empresa Social, Sector No Lucrativo o Economía Participativa, que con matices viene a definir la misma realidad económica.

Las características que definen a este sector de la economía afectan el fin y la estructura de estas organizaciones. Su finalidad es siempre el servicio a sus miembros y/o a la colectividad y no la obtención de

Reformistas del cristianismo en búsqueda de volver a los principios solidarios y comunitarios en su actuar (Idea extraída de "REFLEXIONES: Peter Cornelius Plockboy y la República cooperativa” de Javier Garteiza Urrecoa). 
un beneficio económico para retribuir la inversión de capital, finalidad que caracteriza a las empresas capitalistas (Radrigán, 2007).

Desde el punto de vista de la estructura y funcionamiento, en el año 2002 la Conferencia Europea Permanente de las Cooperativas, Asociaciones, Mutualidades y Fundaciones (CEP-CMAF) aprobó la carta Europea de los Principios Fundamentales de la Economía Social. En el documento se expone que el concepto de Economía Social agrupa a denominaciones utilizadas en varios países como economía solidaria o tercer sector y destaca como principios que la caracterizan los siguientes:

- Primacía del hombre y del objeto social sobre el capital, a excepción de las fundaciones todas son empresas de personas.

- Adhesión voluntaria y abierta y control democrático por sus miembros desde la base.

- $\quad$ Conjunción de los intereses de los miembros usuarios y/o de interés general.

- $\quad$ Defensa y aplicación del principio de solidaridad y de responsabilidad.

- $\quad$ Autonomía de gestión e independencia de los poderes públicos.

- La mayor parte de los excedentes se destinan a la consecución de los objetivos a favor del desarrollo sostenible, el interés de los servicios a los miembros y el interés general.

\subsubsection{Antecedentes del Marco Jurídico del Sector Cooperativo}

En Chile el cooperativismo ha estado regulado por la Ley General de Cooperativas 19.832 del año 2003 actualizada por última vez el año 2016, la cual a través de su propio Reglamento regula aspectos como su naturaleza jurídica, los socios que la componen, su capital y excedente, su estructura organizacional y administrativa, su disolución, fusión, división, transformación y liquidación, las sanciones, privilegios y exenciones, los tipos de cooperativas (agrícolas, campesinas, de trabajo, de servicio, de consumo, pesqueras, especiales agrícolas y de abastecimiento de energía), entre otros aspectos.

Según la Ley General de Cooperativas publicada el 6 de enero de $2016^{6}$, las cooperativas escolares hacen parte de las "Cooperativas de Servicio" puesto que tienen "por objeto distribuir los bienes y proporcionar servicios de toda índole, preferentemente a sus socios, con el propósito de mejorar sus condiciones ambientales, económicas y de satisfacer sus necesidades familiares, sociales, ocupacionales o culturales" (Ley $\left.\mathrm{N}^{\circ} 19.832,2016\right)$. Cuenta además con tres artículos que exponen su propósito, finalidad y la forma de administrar los recursos económicos de las cooperativas escolares de forma específica, son los siguientes:

Art. 69: "Son cooperativas escolares las que se constituyen en los establecimientos de educación básica, media, especial o superior, con el objeto de propender al mejoramiento de las escuelas en las cuales se fundan y de la comunidad en que éstas funcionan. El propósito principal de las cooperativas escolares es educativo y secundariamente económico".

Art. 70: "Las finalidades de estas cooperativas deberán ser las de proporcionar útiles escolares o servicios que propendan al desarrollo cultural, social y físico de la comunidad educativa. Los estatutos señalarán específicamente estos fines y los medios a través de los cuales serán llevados a la práctica, todo conforme a las normas que fije el reglamento".

"Las cooperativas escolares estarán exentas de todos los impuestos fiscales y municipales. Salvo del impuesto al valor agregado contemplado en el Decreto Ley N825, de 1974”.

Art. 71: "Las cooperativas escolares no distribuirán sus beneficios económicos, los cuales se dedicarán a la constitución de un fondo de reserva y un fondo de desarrollo".

\subsection{Emprendimientos Asociativos}

El emprendimiento asociativo nace como concepto en el mundo académico desde finales del siglo XVIII, Radrigán (2007) asegura que las teorías que diferencia el concepto de empresario y de emprendedor son bastante recientes, encontrándose una primera referencia a esta diferencia por Levesque (2002) donde se hace referencia a autores como Richard Cantillon, Max Weber y Joseph Schumpeter; quienes diferencian estos dos tipos de emprendedores y caracterizan al empresario tradicional y asociativo.

El concepto de emprendimiento asociativo se desprende de las palabras que lo componen, en la investigación la palabra emprendimiento es entendida como la acción de una persona de llevar a cabo una idea, un proyecto, un propósito teniendo metas y objetivo claros y definidos. Por otro lado, ser asociativo responde a la necesidad del "ser social", es decir de agruparse en un conjunto de personas. La definición de emprendimiento asociativo más apropiada para esta investigación corresponde a la idea del "emprendedor colectivo o asociativo", propuesta por Mario Radrigán en "Procesos educativos, juventud y desarrollo de la capacidad emprendedora asociativa. Lecciones de análisis de experiencias internacionales" donde identifica tres tipos de emprendedores:

6 Diario Oficial 25 de enero 2007. Aprueba Reglamento de la Ley General de Cooperativas, 2004 Ministerio de Economía, Fomento y Reconstrucción. 
Emprendedor capitalista: Para Radrigán es la persona que tiene la capacidad de innovar y desarrollar ideas centradas en un proyecto con ánimo de lucro, racionalidad instrumental y capacidad de asumir riesgos.

Emprendedor social: Este emprendedor es descrito por Radrigán como una persona que además de tener las características del emprendedor capitalista, suma o reemplaza la orientación del lucro, planteándose entonces un objetivo centrado en el desarrollo de la comunidad a través de la provisión de un bien o un servicio que no se encuentra disponible para un colectivo de la población. Por lo general, aunque no siempre, estas iniciativas se concretizan a través de una organización sin ánimo de lucro. Sin embargo, aunque el emprendedor social sea capaz de movilizar activamente ciertas energías y recursos de su entorno, su "empresa social" estará centrada en su persona y sus capacidades, por lo menos en la etapa inicial de su emprendimiento.

Emprendedor colectivo o asociativo: Para Radrigán, este emprendedor suma a las características descritas anteriormente, dos rasgos particulares, primero, un desarrollo en el marco de un colectivo de personas que hará que el concepto de emprendedor siempre tenga un carácter plural, aunque se pueden identificar liderazgos claros a su interior. También la necesidad de una modalidad de gestión centrada en la democracia y en la búsqueda de consensos que permitan los desarrollos de la iniciativa empresarial con el máximo de recursos disponibles, tanto internos como externos.

\subsection{Cooperativas Escolares: Educación para el Emprendimiento Asociativo}

El concepto de Cooperativas Escolares se origina en 1918, en el periodo de post primera guerra mundial en Francia, de la mano del profesor Barthemely Profit quien, en esa época, propuso un modelo educacional alternativo como respuesta a la destrucción del territorio francés y de los centros educacionales; el propósito principal era la búsqueda de una vía para adquirir mobiliario, útiles y materiales escolares (Galiana, Sastre, Villarroya, 2015:126). Su idea fue próspera y bien acogida en Francia y pronto comenzó a expandirse a otros países como: Suiza, Polonia, Canadá, EEUU, Argentina, Puerto Rico, Ecuador, México, Colombia y Costa Rica (La Alianza Cooperativa Internacional).

Las Cooperativas Escolares son "sociedades de alumnos administradas por ellos con el concurso de los maestros y con vistas a actividades comunes, inspiradas por un ideal de progreso humano basado en la educación moral, cívica e intelectual de los pequeños cooperadores por medio de la gestión de la sociedad y el trabajo de sus miembros" (UNESCO, 2015, ver también Fernández 2000:66-67).

En su tesis de grado, Fernando Ahumada (2017) afirma que los principios de las Cooperativas Escolares deben tener proyección sobre el conjunto de la comunidad educativa, deben incidir en las relaciones personales de quienes trabajan en este tipo de organización, deben repercutir en el aula donde se proyecta el trabajo docente, e incidir en las familias que confían en el trabajo de las cooperativas. Agrega además que, "las cooperativas escolares y los centros de enseñanza de la economía social mejoran el entorno donde se desarrollan y tienen el deber de comprometerse con las inquietudes de sus participantes, ese sentido de responsabilidad social debe estar impregnado en los estatutos de las cooperativas y el modelo organizativo; consecuentemente fomentar la resolución de conflictos a través de la colaboración y cooperación". (ver también Fernández, 2003:55 y Martín, Fernández, Bel \& Lejarriaga 2013:76-77)

El documento "Modelos educativo para los centros de Economía Social - Propuesta en Construcción" realizado en Andalucía, España, por la Asociación Andaluza de Centros de Enseñanza de la Economía Social, identifica los siguientes principios que deben estar presentes en el día a día de las cooperativas escolares:

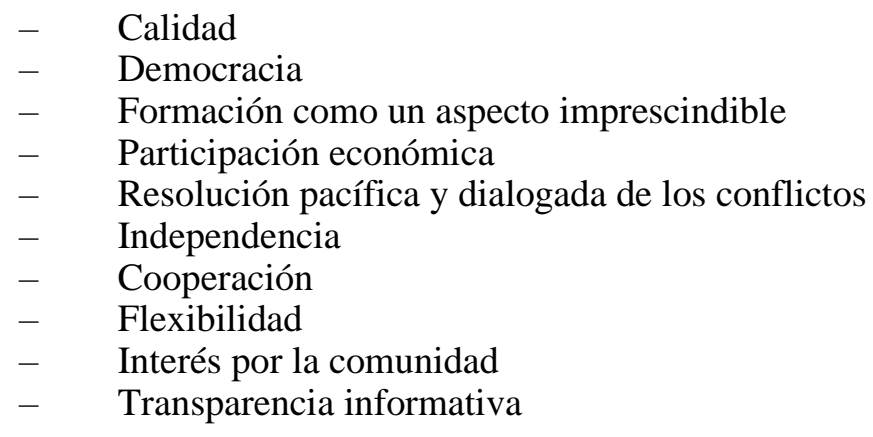

La organización escolar es un subsistema que alimenta a la comunidad, con la distribución de valores, conocimientos y habilidades, cuyos efectos benefician a su entorno y señalan modelos de actuación que influyen en quienes reciben su influencia. Por todo lo anterior, la dimensión cooperativa tiene un rol coadyuvante en la consecución de los fines más trascendentales instituidos por la escolaridad, en su aporte al bien común (Radrigán, Silva y Rodríguez; 2000). 


\section{Metodología}

El objetivo general de este trabajo es describir y analizar la influencia de las cooperativas escolares en la formación de los niños y adolescentes que participaron en ellas. Este objetivo se cumplirá a través de objetivos específicos, los cuales son:

- Caracterizar a los estudiantes que participan o participaron en una cooperativa escolar (en cuanto a su género, edad actual, edad al momento de ingresar y nivel educacional);

- Identificar el aprendizaje que obtuvieron estos estudiantes; identificar las aptitudes adquiridas; y,

- Conocer la opinión que tienen los estudiantes sobre el funcionamiento de las cooperativas escolares y si son una buena práctica.

Para la consecución de estos objetivos se han planteado una serie de preguntas que buscan orientar la investigación:

- ¿Cuáles fueron los aprendizajes (personal, valórica y profesional) que obtuvieron los estudiantes al participar en la gestión de la cooperativa escolar?

¿Cómo es la participación estudiantil en las cooperativas escolares?

- $\quad$ ¿Qué factores motivacionales permiten la creación y gestión de la cooperativa escolar?

La investigación realizada es descriptiva, no probabilístico, donde se realizó un método de muestreo consecutivo, cuyo universo contó con 142 estudiantes que participan o participaron activamente en cooperativas escolares de seis colegios de la Región Metropolitana. Los colegios que participaron en este estudio fueron:

- Colegio Unión Nacional Árabe.

- $\quad$ Escuela Futuro Las Mercedes.

- $\quad$ Escuela República de Israel.

- $\quad$ Escuela Poeta Neruda.

- Instituto Superior de Comercio.

- Colegio Josefina Gana de Johnson.

La metodología utilizada en esta investigación tiene un enfoque cuantitativo donde se "utiliza la recolección y el análisis de datos para contestar preguntas de investigación y probar hipótesis establecidas previamente, y confía en la medición numérica, el conteo y frecuentemente en el uso de la estadística para establecer con exactitud patrones de comportamiento en una población" (Hernández, Fernández y Baptista, 2003) y como señalan Grinell y Creswell (1997) no se desechan la realidad subjetiva ni las experiencias individuales.

Las técnicas utilizadas en este estudio contaron con la obtención de la información, análisis y discusión para la realización de un marco referencial sobre el tema de investigación. También se entrega información que se obtuvo a través de una encuesta aplicada a los estudiantes que han participado en una cooperativa escolar, con información relevante a la formación que obtuvieron de dicha experiencia, para finalizar con el análisis de los datos obtenidos y la entrega de una propuesta a la investigación.

Como toda investigación, esta también contó con limitaciones que correspondieron a las escasas cooperativas escolares que se encuentran en funcionamiento activo en la Región Metropolitana, el tiempo de recolección de datos y el difícil acceso a la información relacionada. Por otro lado, está el límite temporal, el cual se sitúa entre los años 2000 y 2016, periodo que comprende el año en que se creó la primera de las cooperativas escolares encuestadas y posteriormente la creación de otras cooperativas escolares en otros centros educacionales a la fecha. 


\subsection{Caracterización de los estudiantes encuestados que hacen o hicieron parte de una cooperativa escolar}

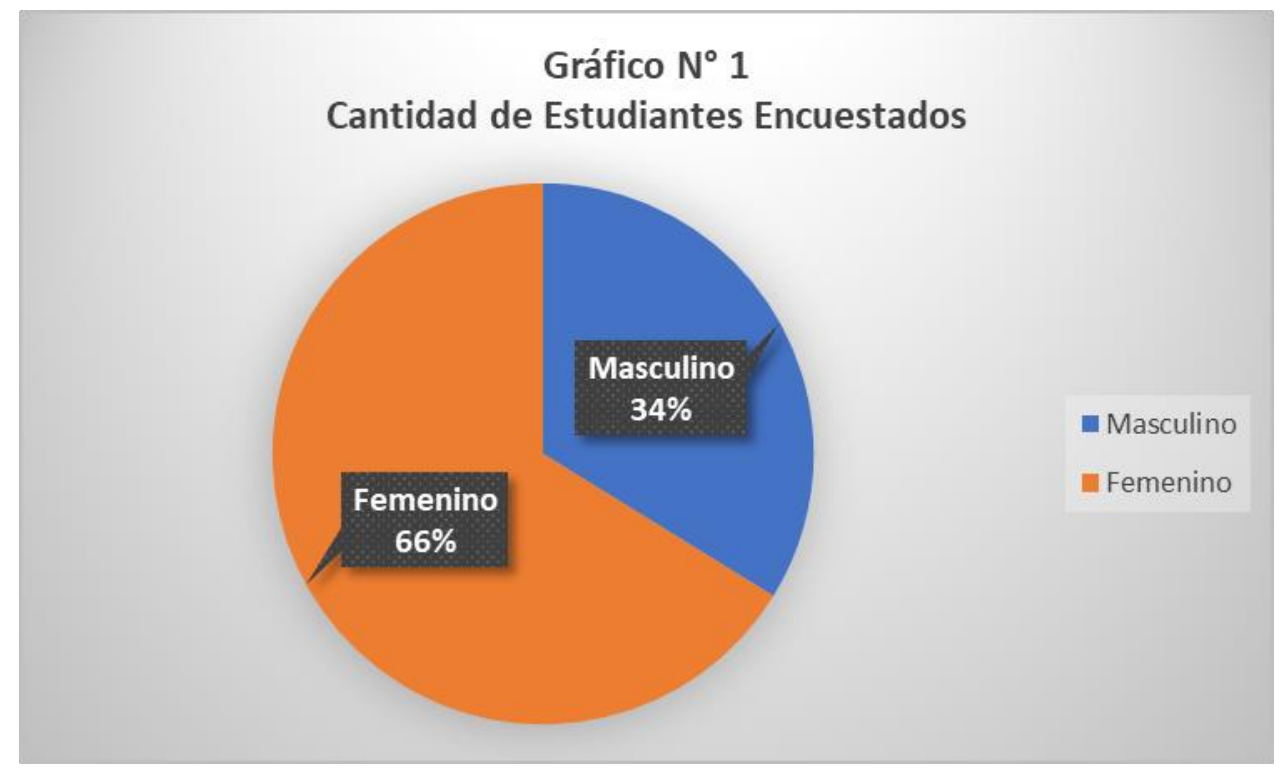

Fuente: Elaboración propia.

Este estudio contó con una muestra compuesta por 142 estudiantes que pertenecieron alguna vez o pertenecen en la actualidad a una cooperativa escolar; donde un $67 \%$ son mujeres y un $34 \%$ son hombres. La explicación para entender por qué hay un mayor porcentaje de mujeres que de hombres, se debe principalmente a factores de comportamiento y refuerzos en los aprendizajes adquiridos tanto en la escuela como fuera de ella, que diferencian a ambos sexos. La alta participación femenina con relación a la masculina se podría deber a factores motivacionales, de madurez, estímulos y refuerzos educativos ya dispuestos y diferenciados entre niños y niñas, lo que en sí abre una interesante línea de investigación y reflexión.

Las edades de los estudiantes que participan activamente en cooperativas escolares se encuentran entre los 10 y 19 años, sin embargo, se puede observar un alza en la participación entre los 14 y 17 años, mientras que la participación vuelve a disminuir entre los 18 y 19 años. De este gráfico se desprende que es durante la enseñanza media que aumenta significativamente la participación de los alumnos en sus respectivas cooperativas escolares, sufriendo una disminución natural de participación por parte de los estudiantes de cuarto medio, quienes están muy cerca de egresar y además dejan de ser socios de la cooperativa al perder su calidad de "alumno regular"; los reglamentos de las cooperativas escolares encuestadas impiden que un alumno egresado sea parte de su gestión.

En el gráfico también se puede observar que, aunque los socios de las cooperativas escolares dejan de serlo cuando egresan de cuarto medio, la distribución de la edad va desde los 10 años hasta los 34, esto debido a que la encuesta también contempló a egresados de los colegios que alguna vez fueron socios de la cooperativa escolar instalada en cada uno de los recintos educacionales donde se realizó el levantamiento de la información. 


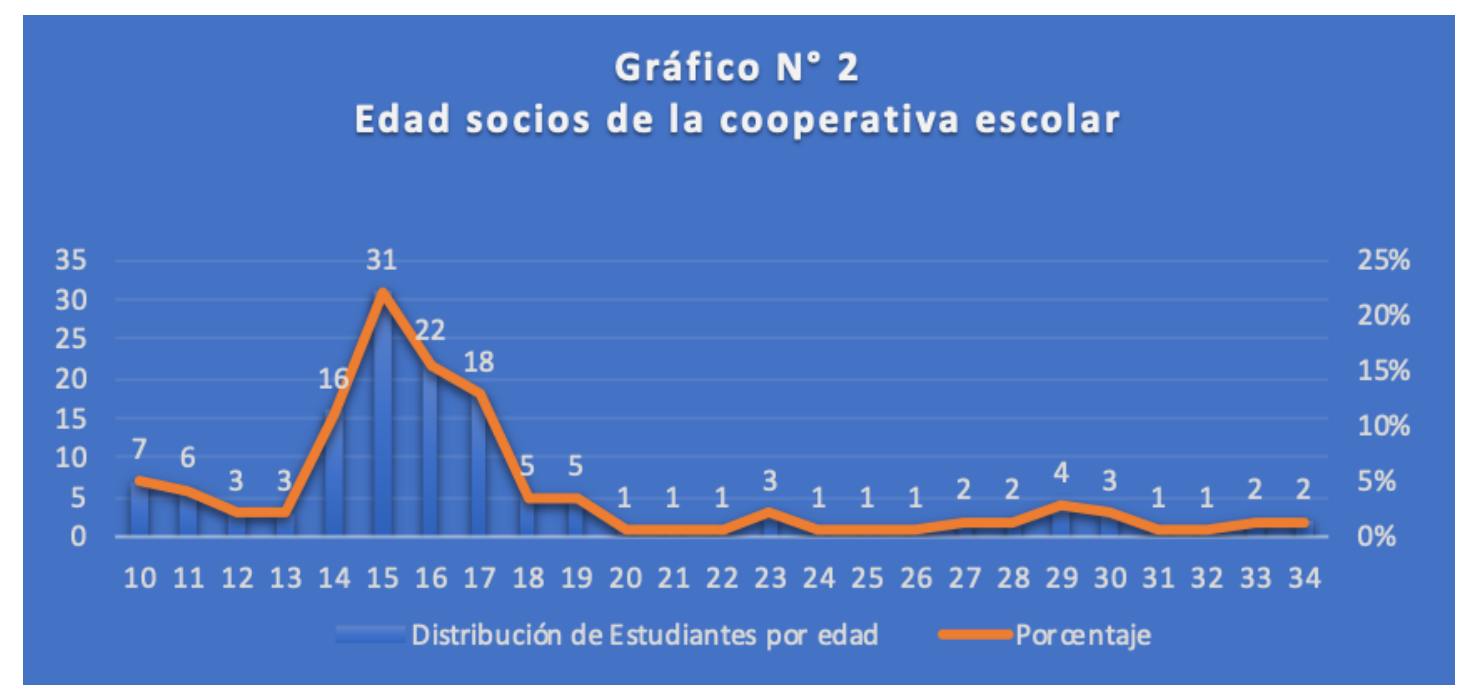

Fuente: Elaboración propia

\subsection{Número de Estudiantes Encuestados por Colegio}

El 82.39\% de los estudiantes encuestados pertenecen al Instituto Superior de Comercio 11 (INSUCO), luego de forma descendente la Escuela República de Israel E-50 con un 7.74\%, el Colegio Josefina Gana con un 7.04\%, la Escuela Poeta Neruda con un $1.40 \%$, el Colegio Unión Nacional Árabe y la Escuela Futuro Las Mercedes con un $0,70 \%$, como se muestra en el Gráfico ํ⒊

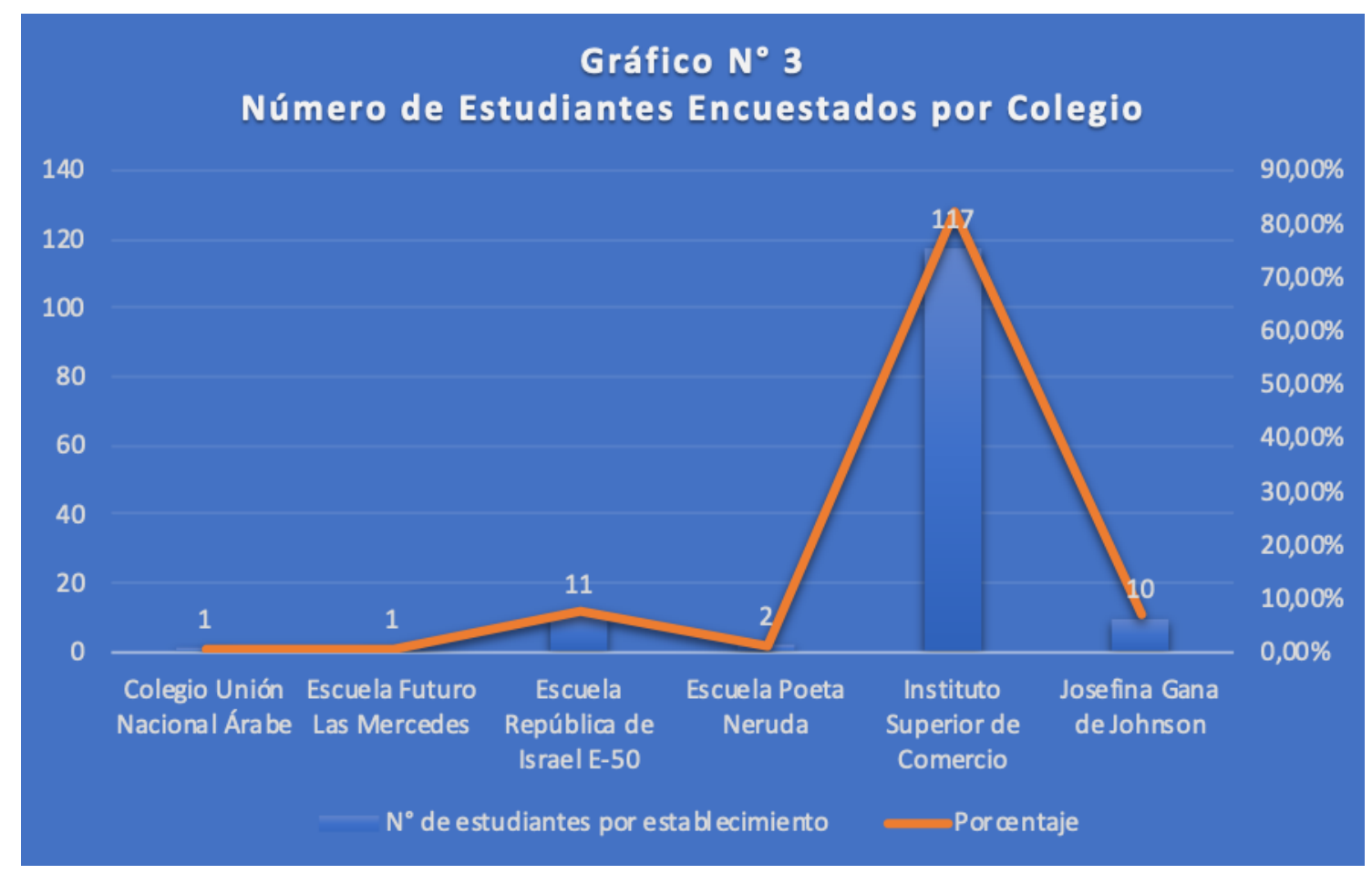

Fuente: Elaboración propia

La diferencia entre los seis colegios se debe principalmente a tres grandes factores, el primero tiene que ver con la antigüedad de la cooperativa escolar del Instituto de Comercio que lleva alrededor de 20 años de existencia, lo segundo es la diferencia entre la cantidad de estudiantes de los colegios encuestados y finalmente, el rubro de las propias cooperativas determina (en gran medida) la cantidad de participantes. Por una parte, la cooperativa escolar del Instituto Superior de Comercio realiza eventos artísticos y culturales con un gran número de estudiantes en una puesta en escena, mientras que el Colegio Josefina Gana de Johnson, la Escuela República de Israel, la Escuela Poeta Neruda y el Colegio Unión Nacional Árabe centran las actividades de la cooperativa en un sistema de venta de artículos escolares en un kiosco tipo bazar, por lo tanto, no requieren de una gran cantidad de participantes. En el caso de la Escuela Futuro Las Mercedes, la 
cooperativa centra sus labores en las actividades agrícolas, principalmente en un huerto con plantas medicinales, requiriendo una cantidad moderada de socios en la cooperativa.

\section{Resultados}

A continuación, se presentan los principales resultados de la investigación de campo realizada, en donde se ha puesto principal atención a la valoración que los propios estudiantes han hecho de su participación en la cooperativa escolar

\subsection{Curso al momento de ingresar}

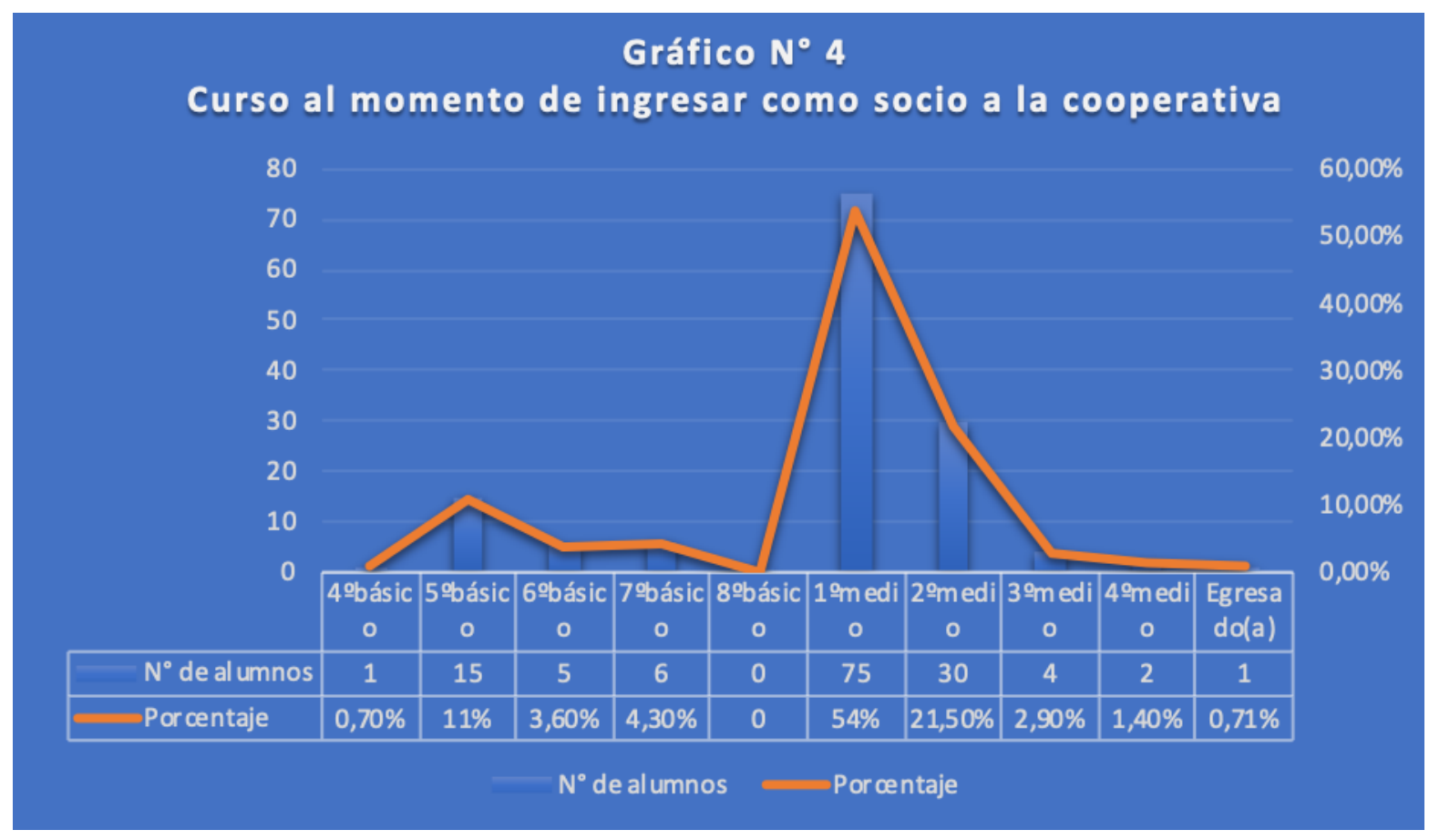

Fuente: Elaboración propia

El gráfico $\mathrm{N}^{\circ} 4$ refleja que la gran mayoría de los estudiantes que fueron entrevistados ingresaron a la cooperativa escolar al comenzar la enseñanza media. 54\% de los estudiantes ingresan en primero medio y $21,50 \%$ lo hacen en segundo medio. En el gráfico también se destaca que existen alumnos que ingresan a la cooperativa escolar en quinto básico (correspondiente a la tercera mayoría).

También es posible observar dos descensos, el primero corresponde a la enseñanza básica y el segundo a la enseñanza media, en ambos descensos se divisa que dejan de ingresar a la cooperativa escolar en los últimos años de cada ciclo de formación, esto debido a que los estudiantes de $8^{\circ}$ básico, $3^{\circ}$ medio y $4^{\circ}$ medio se encuentran preparándose para ingresar a nuevos ciclos educacionales y deben asumir nuevas responsabilidades conforme su educación avanza, de igual forma los estudiantes deben administrar sus tiempos de mejor manera, es decir, deben planificar y evaluar si los tiempos de estudio y los de trabajo cooperativo son compatibles entre sí; por lo tanto, en el Gráfico $\mathrm{N}^{\circ} 4$ se manifiesta la incertidumbre en cuanto al ingreso a la cooperativa en los tres niveles ya mencionados, no pasa lo mismo con los demás niveles educacionales, donde los estudiantes ya tienen bien definidas sus rutinas de estudios y establecidas, reconociendo entonces, el esfuerzo que deben realizar para llevar a cabo sus tareas estudiantiles, lo que les permite decidir de mejor manera su participación en la cooperativa escolar. 


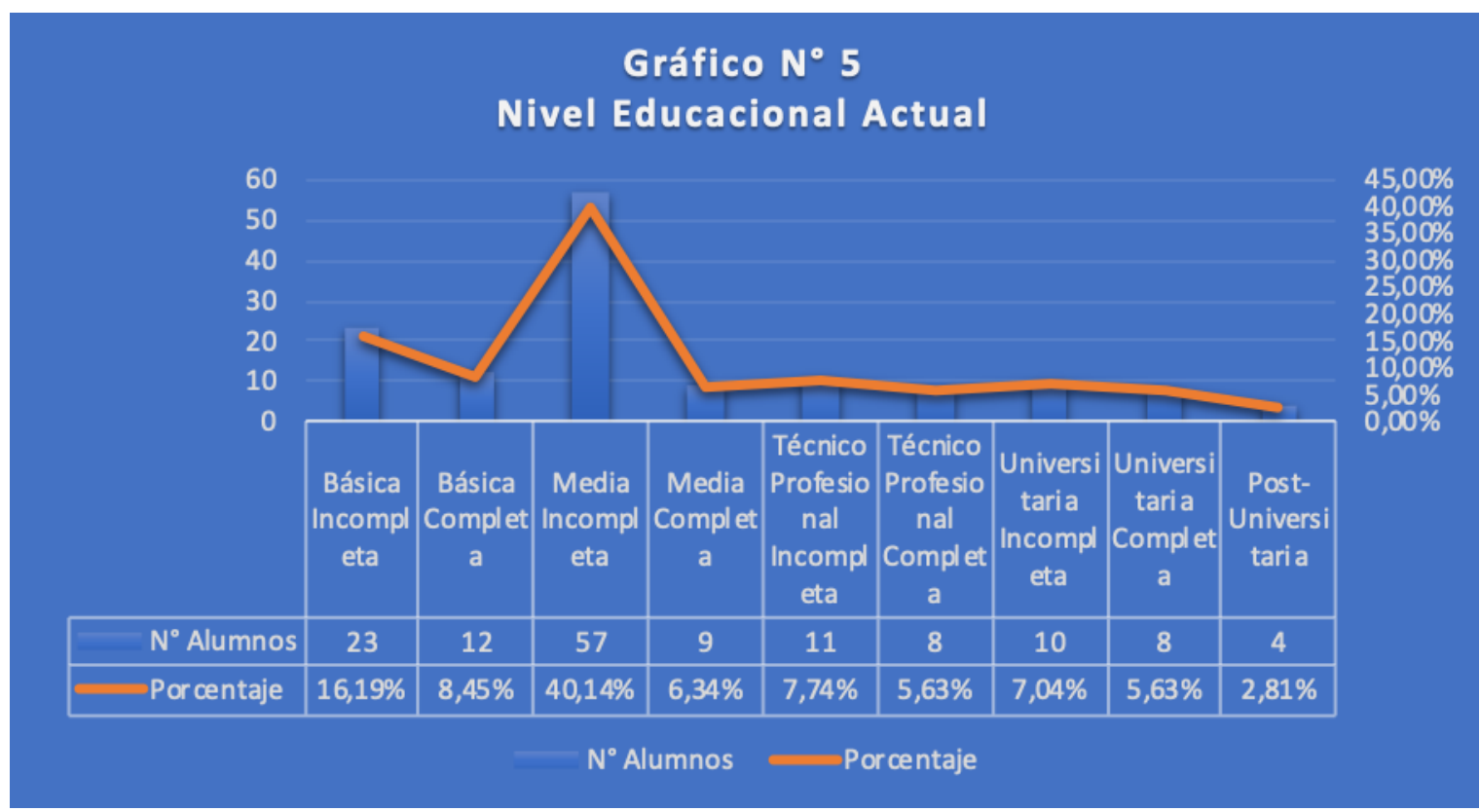

Fuente: Elaboración propia

El Gráfico $\mathrm{N}^{\circ} 5$ nos permite observar que el nivel educacional de los estudiantes encuestados se concentra principalmente en la educación media incompleta con un 40,14\%; alcanzando la educación media un total de $46.48 \%$ de estudiantes pertenecientes a las cooperativas escolares, en contraste con un $24.64 \%$ de alumnos pertenecientes a la educación básica que hacen parte también de las cooperativas escolares.

\subsection{Caracterización del establecimiento y la cooperativa}

\subsection{2. ¿Cómo tuvo conocimiento de la Cooperativa Escolar?}

A través del gráfico se puede observar que, de los 142 estudiantes encuestados, el $69 \%$ manifestó que obtuvieron conocimiento de la cooperativa escolar a través del "profesor asesor", esto se debe principalmente a que las cooperativas tienen como principal asesor a un profesor que ha sido capacitado para ayudar a los estudiantes en la ejecución de su emprendimiento.

El 17,60\% de los estudiantes encuestados respondió haberse enterado del proyecto de cooperativas escolares a través de los amigos, esto se debe principalmente a que los socios de la cooperativa escolar logran visualizar los logros personales y grupales que obtienen al momento de trabajar en ella, por lo tanto, se socializa dicha información y se traspasa a otros estudiantes de los colegios. 


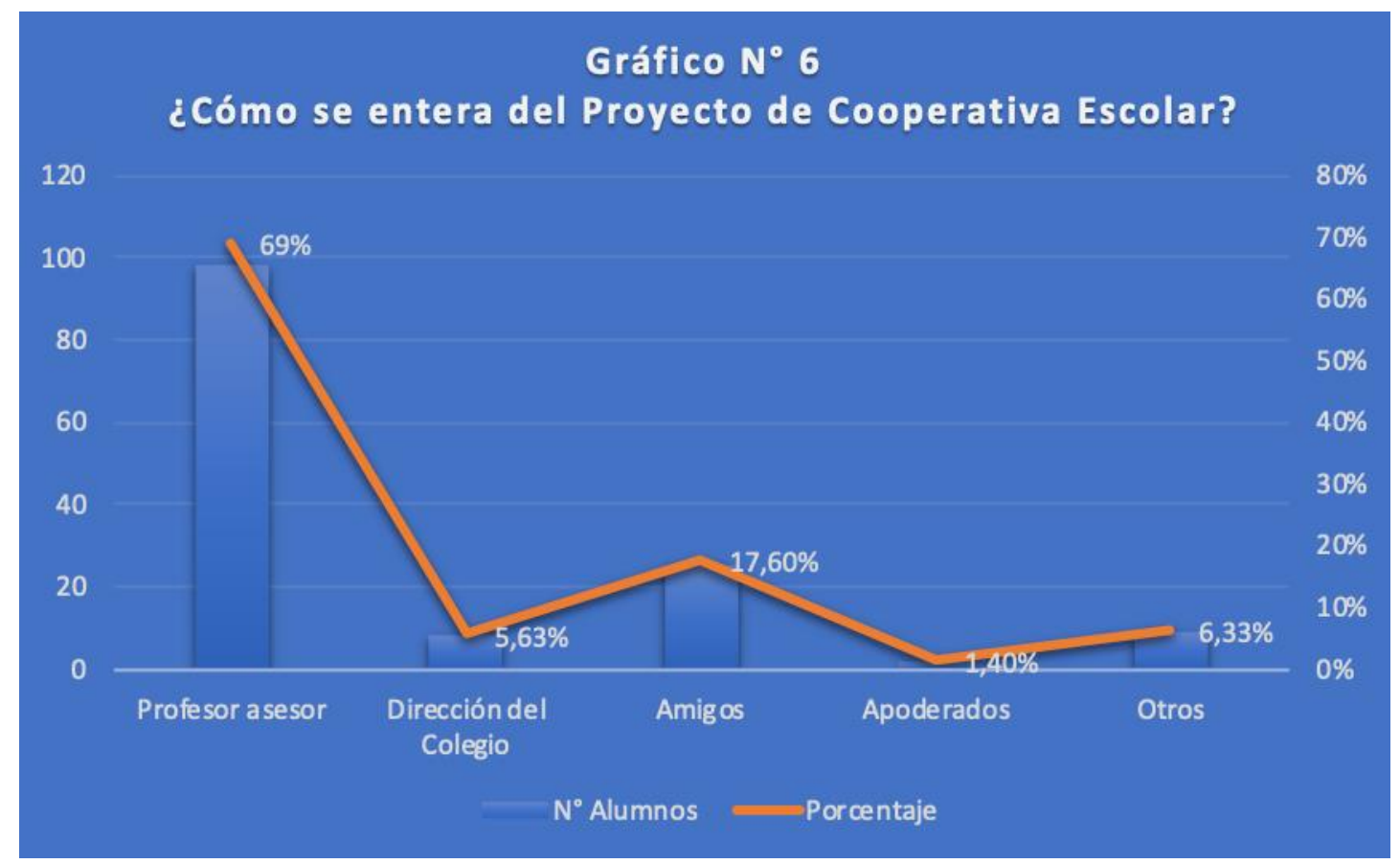

Fuente: Elaboración propia

En este punto es importante mencionar que a través de la información recopilada se puede inferir que no existe fomento por parte del Estado en cuento a la difusión de las cooperativas escolares en alumnos de enseñanza básica y media, lo cual deja en evidencia la falta de políticas públicas asociadas al nivel educacional del cooperativismo

\subsection{3. ¿Qué tipo de Aprendizaje obtuvo al interior de la Cooperativa Escolar?}

Dadas las condiciones iniciales de la pregunta, es posible observar que la mayoría de los estudiantes prefieren detallar el tipo de aprendizaje que obtuvo al interior de la cooperativa escolar antes que centrarlo en algunos de los aspectos básicos que se aprenden en las escuelas de administración, economía y negocios; por lo tanto, la interpretación del Gráfico $\mathrm{N}^{\mathrm{0}} 7$ se centra en las últimas cuatro opciones más votadas, dejando para el Gráfico $\mathrm{N}^{\mathrm{o}} 8$ el análisis y la interpretación de las categorías de las respuesta "Otros".

El gráfico $\mathrm{N}^{\mathrm{o}} 7$ nos permite observar que un $35.8 \%$ de los encuestados seleccionó Administración, un 18,2\% Contabilidad, un 10,2\% Finanzas, un 8,0\% Derecho. Es necesario destacar que las cantidades y los porcentajes no tienen que ver con el número de personas encuestadas sino con la posibilidad que tuvieron de poder seleccionar más de una opción de respuesta.

A través del gráfico también se puede observar que la opción "Contabilidad" cuenta con un 18,2\% transformándose en la segunda opción más seleccionada por los alumnos encuestados (sin tener en cuenta la opción "Otros"). Respecto a la "Contabilidad" es posible mencionar que el acercamiento a este aprendizaje se lleva a cabo principalmente en la administración del dinero que recauda la cooperativa escolar, el orden y el análisis de la economía de la cooperativa escolar, teniendo presente los elementos básicos de esta área, los estudiantes y socios de la cooperativa administran los ingresos, los gastos, el capital, los programas de caja, el patrimonio, etc.

En cuanto al aprendizaje financiero, este tiene que ver también con actividades que se realizan al interior de la organización, por ejemplo, la cooperativa escolar busca la inversión de forma solidaria, es decir, invertir en mejorar las instalaciones de infraestructura y el equipamiento del establecimiento educacional, ya que el objetivo principal de la cooperativa escolar tiene que ver principalmente con la educación, por lo tanto, la inversión busca mejorar la calidad de vida de los estudiantes, como también financiar actividades escolares. En pocas palabras, se busca planificar que el destino de los recursos beneficie a toda la comunidad escolar y permita el crecimiento de la cooperativa. 


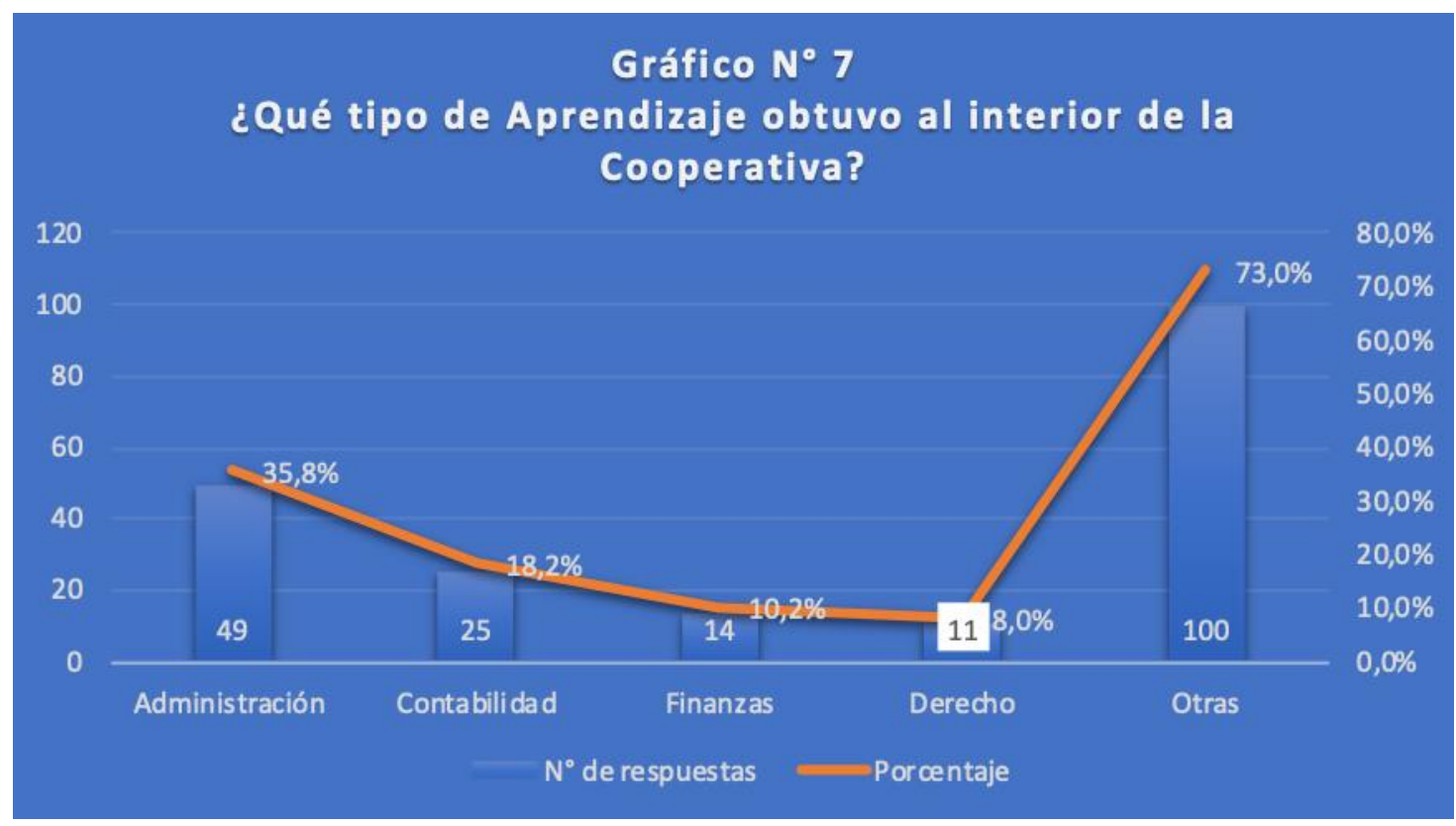

Fuente: Elaboración propia

Finalmente, cuando los estudiantes hablan de un aprendizaje en "Derecho" se están refiriendo a la aplicación práctica de los derechos humanos hasta aspectos de la educación cívica. Las prácticas que se realizan al interior de la cooperativa escolar están en marcadas en principios de libertad, igualdad, razón, conciencia y fraternidad; mencionados en el Artículo 1 de la Declaración Universal de los Derechos Humanos (DUDH $)^{7}$, esto sucede porque dichos principios son parte de las actividades diarias de una cooperativa al fomentar la inclusión, el trabajo en equipo, el respeto de las creencias, opiniones y expresiones tanto de los integrantes de la cooperativa como por su entorno (Art $\mathrm{N}^{\circ} 18$ y $\operatorname{Art~}^{\circ} 19$ DUDH).

La respuesta "Otros" fue desglosada en siete categorías para una mejor comprensión y enriquecimiento del análisis y será analizada en el siguiente gráfico.

\subsubsection{Detalles de otros aprendizajes}

De los 85 estudiantes que seleccionaron la opción "Otros" en el Gráfico № 7, el 34\% afirmó que aprendió "Trabajo en Equipo", un 21\% obtuvo un aprendizaje en "Formación Artística", un 8\% señala que aprendió "Habilidades Técnicas Profesionales", un 7\% aseguró haber aprendido habilidades blandas, un 5\% y un 4\% señala haber aprendido actitudes y valores morales respectivamente. Es importante resaltar en este punto que, a versatilidad de las cooperativas escolares permiten desarrollar diversos tipos de aprendizajes en sus socios y el aprendizaje se realiza de forma activa, es decir se aprende haciendo. 


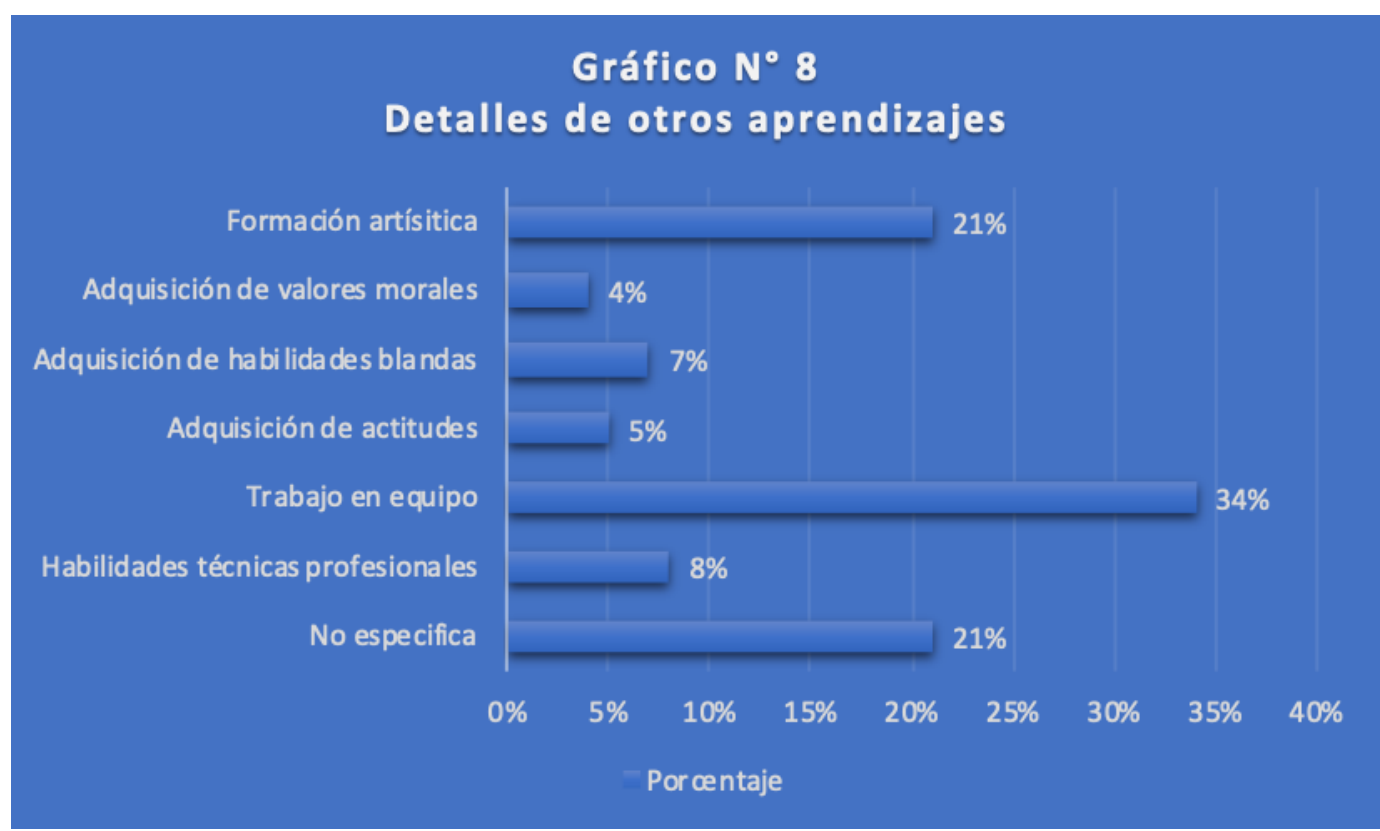

Fuente: Elaboración propia

\subsubsection{Actividades desempeñadas al interior de la Cooperativa Escolar}

El Gráfico $N^{\circ} 9$ nos permite observar las actividades que los estudiantes desempeñaron al interior de la cooperativa. Las categorías que obtuvieron mayor porcentaje corresponden a las "Artes Musicales" y el "Baile" con un 33\% y un 26\% respectivamente. Por "Artes Musicales" se entienden todas las actividades instrumentales como la estudiantina, los grupos de rock y otras presentaciones de índole musical. El "Baile" contempla las actividades de danza contemporánea, cueca y otras presentaciones de folklor nacional.

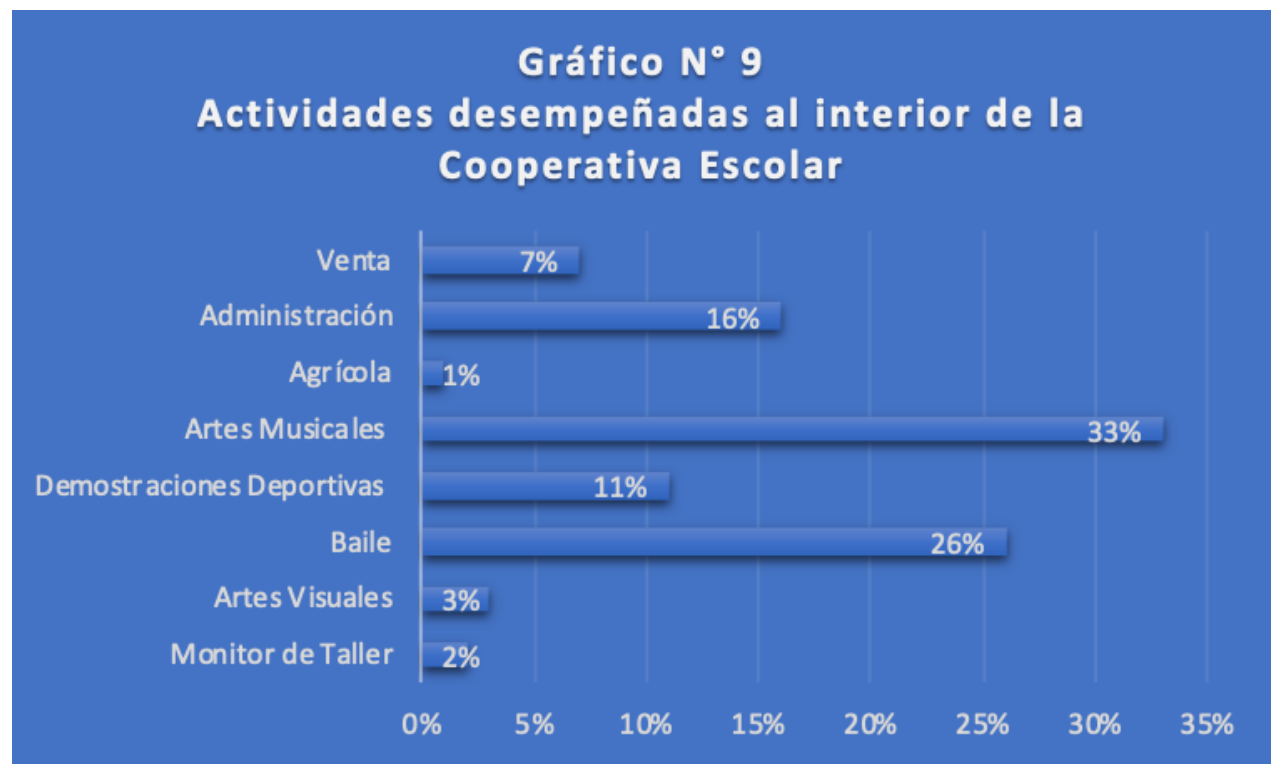

Fuente: Elaboración propia

La categoría "Administración" se encuentra en tercer lugar con un $16 \%$ del total de los encuestados. En este punto se hace necesario aclarar que, aunque todos los estudiantes que participan de la cooperativa escolar lo hacen de manera activa, a través de su opinión y su voto en la toma de decisiones; existen delegados para gestionar cada actividad que se desarrolla en la cooperativa escolar, es por esta razón que los estudiantes que dicen participar en la categoría "Administración" son una cantidad moderada.

En el cuarto lugar están las "Demostraciones Deportivas" representando el 11\% de los encuestados. Esta categoría reúne solo a los integrantes del grupo Cheerleader del Instituto Superior de Comercio, quienes realizan demostraciones acrobáticas y de destreza física. 


\subsubsection{Aptitudes desarrolladas al interior de la Cooperativa Escolar}

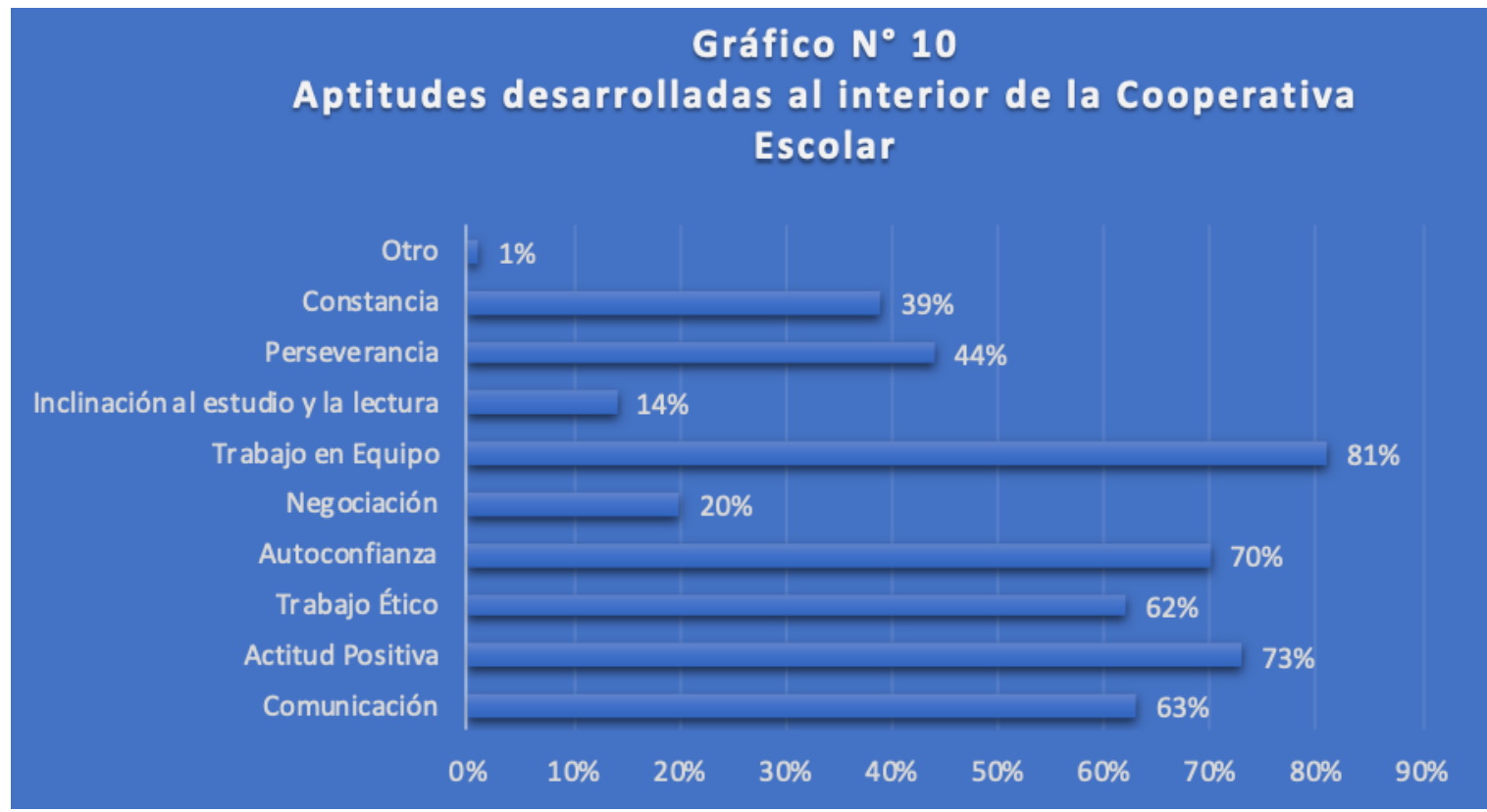

Fuente: Elaboración propia

Según el Gráfico No 10 el 81\% de los encuestados seleccionó el "Trabajo en Equipo" como la aptitud que más desarrollaron, básicamente el trabajo en equipo es la base de la organización cooperativa y los estudiantes lo comprenden al ver los logros reflejados en su trabajo y el bienestar general de la comunidad estudiantil gracias a la cooperación y la solidaridad.

En segundo lugar, se encuentra la "Actitud Positiva" con un 73\%, que se traduce en la exteriorización de las personalidades positivas de los estudiantes que participan en la cooperativa escolar, esto quiere decir que enfrentan los problemas como un nuevo desafío y se proponen lograrlos con entusiasmo, lo cual fomenta a su vez el trabajo en equipo y otras aptitudes en beneficio de la comunidad.

Luego se encuentra la "Autoconfianza" con un 70\% que demuestra que la participación en la cooperativa escolar les ha ayudado a reforzar la confianza en sus capacidades, en sus habilidades para lograr alcanzar sus objetivos y en respetar sus competencias.

Con un 63\%, la "Comunicación" corresponde a la cuarta aptitud más votada, esto corresponde al desarrollo de "habilidades blandas", que en este caso corresponden a la comunicación verbal y no verbal, aportando al nivel de comprensión de los estudiantes en diferentes ámbitos, ya sea en la transmisión de mensajes entre ellos mismos como los gestos y expresiones corporales con el fin de contribuir al buen funcionamiento de la cooperativa.

Con un 62\% el "Trabajo Ético" es la quinta aptitud más votada por los estudiantes, principalmente se refiere al trabajo de acciones bien vistas por la sociedad y que (en la cooperativa escolar) son fomentadas; las virtudes de dichos comportamientos son ampliamente reconocidas por los miembros de la cooperativa escolar, ya que cada uno de ellos depende y deposita su confianza en los comportamientos de sus compañeros. 


\subsubsection{Valores inculcados en la Cooperativa Escolar}

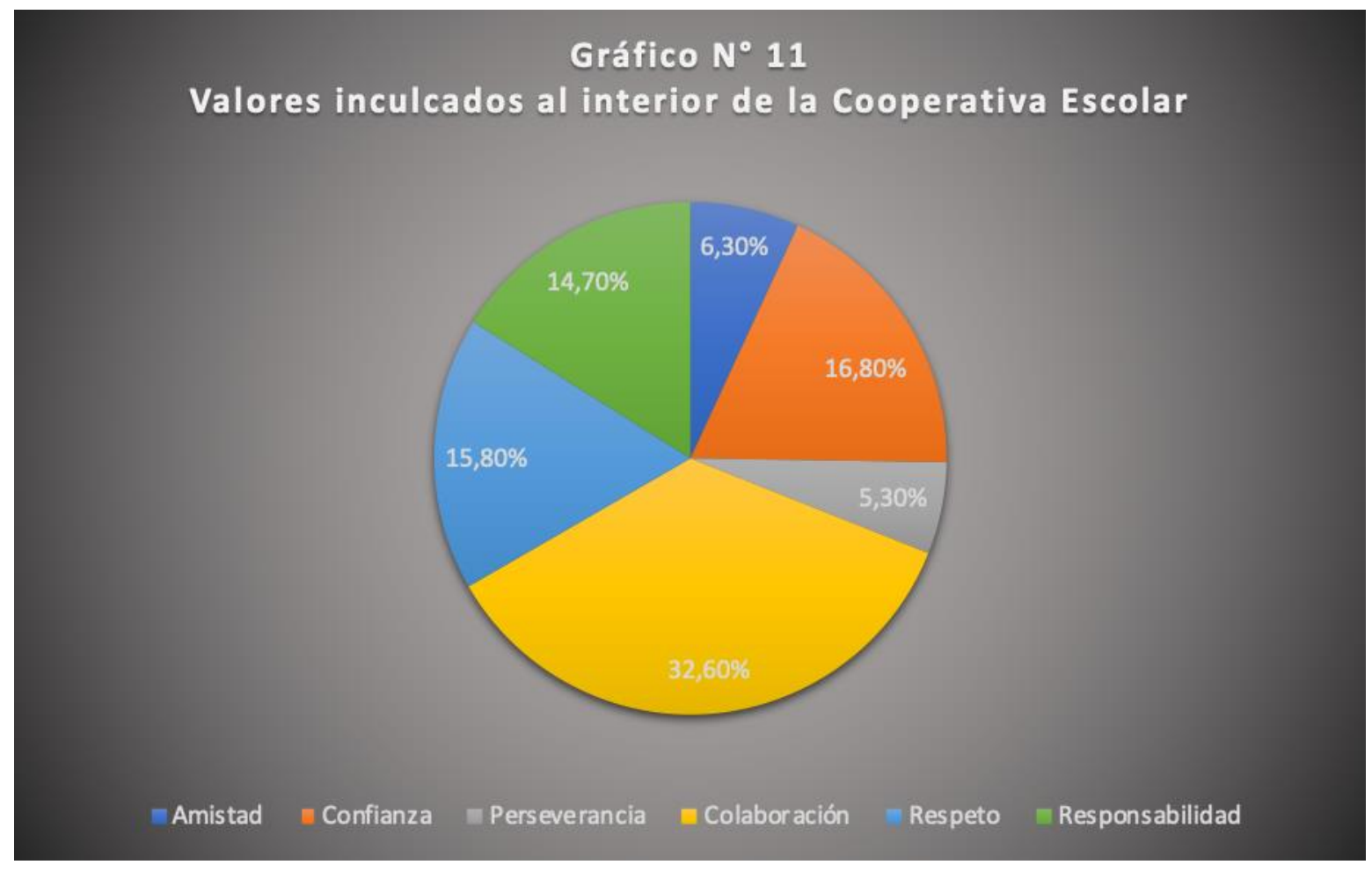

Fuente: Elaboración propia

Según se muestra en el Gráfico N ${ }^{\circ} 11$ la "Colaboración" fue la categoría más seleccionada con un 32,6\%, esto precisamente por el carácter de cooperación y solidaridad entre los socios de la cooperativa, como se mencionó en el gráfico anterior, los estudiantes logran comprender que el trabajo en equipo es lo más beneficioso para ellos, todos colaboran en las tareas de la forma más equitativa posible.

En segundo lugar, está la "Confianza" con un 16,8\%, esto se debe principalmente a la seguridad que tienen los socios de la cooperativa al realizar trabajo en equipo; para Marcelo Martínez (2001), "la confianza se funda y garantiza principalmente en una ética de la responsabilidad individual, que descansa en el hecho básico de que toda persona cumple y respeta las promesas y compromisos que ha declarado frente a otros. Es la promesa mutua y su cumplimiento lo que asegura el éxito del vínculo con extraños".

El "Respeto" es la tercera categoría más seleccionada con un 15,8\%. En una investigación realizada por Valdés, Mondragón, González, López y González en el 2004, se afirma que la definición de respeto que tiene el adolescente varía dependiendo del grupo o individuo con el que se relacionan, por ejemplo, con respecto al propio individuo, el adolescente busca la identificación, "si no te respetas tú, nadie lo hará"; en el caso de los amigos, se busca el apoyo para que la amistad sea duradera, sirve como estímulo para "conservar la confianza"; en el caso de la familia el respeto surge porque "siempre me demuestran afecto", "para vivir en perfecta comunicación", "porque me respeta".

En cuarto lugar, está la "Responsabilidad" con un $14,7 \%$, esta categoría tiene que ver con que el valor que toman las acciones de los estudiantes al interior de la cooperativa se ven reflejados en el producto que ésta entrega y en el trabajo asociado a ella. Toda acción realizada al interior de la cooperativa tiene consecuencias que serán conocidas por los socios, por lo tanto, los estudiantes buscan llevar a cabo sus tareas de forma consciente, segura y atenta con el fin de proteger a la cooperativa escolar y hacer frente a sus objetivos.

La "Honestidad" es la quinta categoría seleccionada con un $8,4 \%$, hace referencia principalmente a la sinceridad del trabajo realizado por los socios de la cooperativa escolar con el resto de los participantes, la honradez en cuanto al manejo de los recursos y la probidad en aspectos generales en la administración.

El gráfico también nos permite observar que la "Amistad" es la sexta categoría seleccionada con un 6,3\%. La amistad es un factor fundamental en la adolescencia ya que "los adolescentes se sienten cómodos entres sus compañeros, quienes atraviesan los mismos cambios físicos y psicológicos que ellos. Es de mucha ayuda tener amigos que estén viviendo las mismas experiencias y que puedan disminuir las ansiedades de los momentos difíciles" (Galdos de Isusi, 2013).

La perseverancia fue la última opción seleccionada con un 5,3\%. La constancia y dedicación que se le otorga a la cooperativa escolar por parte de sus socios se condice directamente con la participación que se tiene en ella, también los resultados esperados del trabajo justifican el actuar de forma duradera o 
perseverante. Como valor, la perseverancia permite a los estudiantes enfrentar obstáculos que se presentan en el desarrollo de las actividades de la organización.

\subsubsection{Cooperativas Escolares como una Buena Práctica. ¿Sería recomendable incorporarla como asignatura en el colegio?}

El gráfico $\mathrm{N}^{\mathrm{o}} 12$ nos permite observar que un 70,4\% de los estudiantes encuestados opinó que las cooperativas escolares son una buna práctica y que además sería una buena alternativa incorporarla como una asignatura a cursar durante el colegio. Las respuestas asociadas al Gráfico $\mathrm{N}^{\circ} 13$, demuestran que el $100 \%$ de los estudiantes encuestados, está de acuerdo en que las cooperativas escolares son una buena práctica, sin embargo, las diferencias de las respuestas se enfocan en si es o no una buena idea incorporar a la cooperativa escolar como una asignatura a cursar durante el colegio. Es por esto, que se establecieron cuatro categorías para diferenciar que tan seguros estaban los estudiantes con respecto a su opinión sobre la cooperativa creando categorías que se diferencian entre sí: "Son una buena práctica" y "Cree que son una buena práctica", dejando en evidencia que la seguridad y confianza de los estudiantes que participan en la cooperativa escolar es bastante alta.

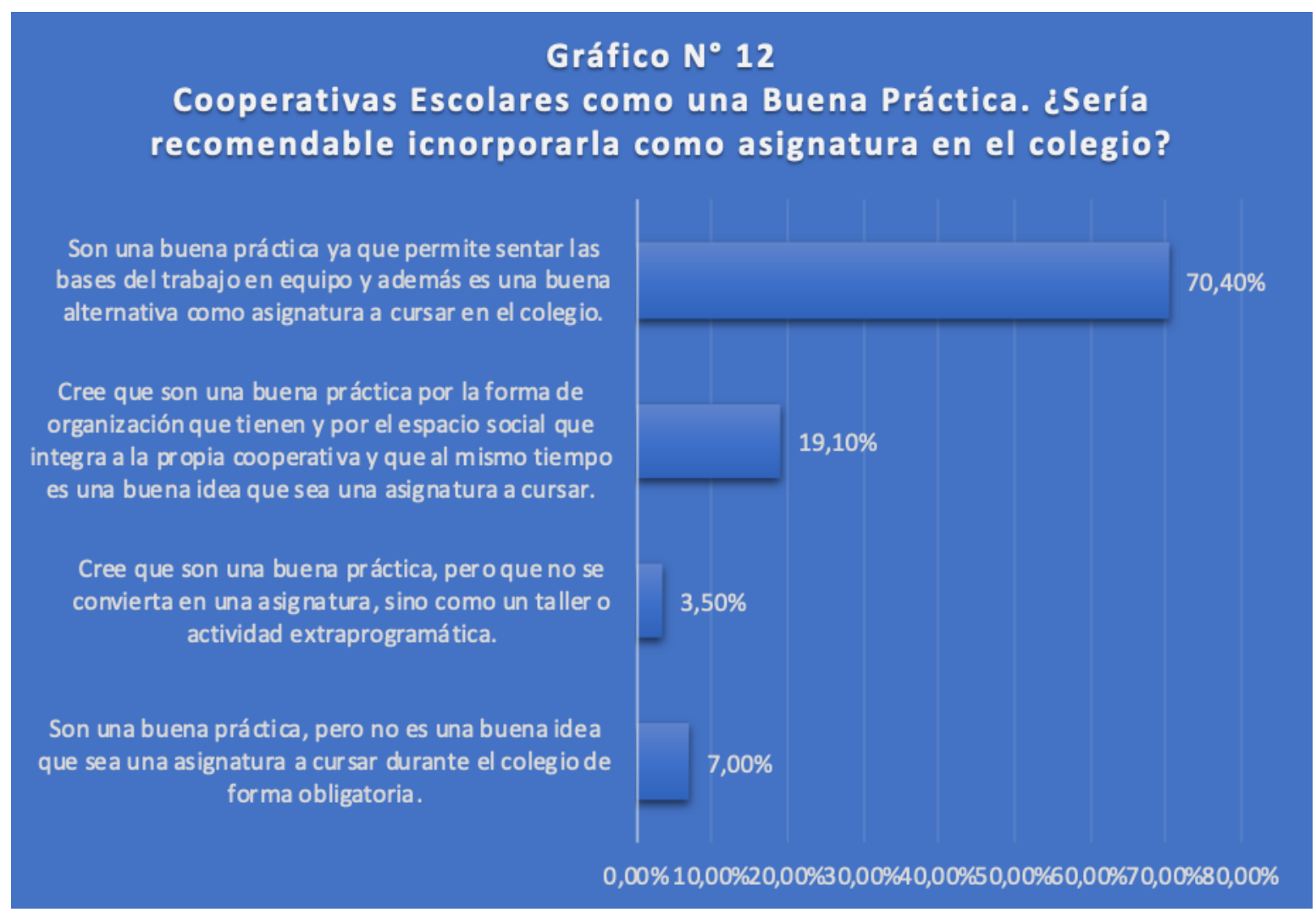

Fuente: Elaboración propia

Por otra parte, también se manifiestan favorablemente con que la cooperativa escolar sea una asignatura que cursar, sin embargo, un grupo menor de estudiantes que son socios de la cooperativa escolar, creen que si fuese de forma obligatoria perdería sus valores democráticos y participativos y que, por lo tanto, sería mejor dejarla como una actividad extraprogramática.

\section{Conclusiones y recomendaciones finales}

\subsection{Conclusiones}

En vista de los objetivos iniciales de la investigación, los antecedentes entregados en el marco teóricoconceptual como de la información levantada en el trabajo de campo, y teniendo en cuenta las principales limitaciones del trabajo realizado (especialmente con lo que dice relación a la dificultad de ubicar a los estudiantes, por el tiempo transcurrido del egreso del establecimiento educacional) se puede concluir que: 
a) Desde la perspectiva de los propios estudiantes su participación en la cooperativa escolar de su establecimiento ha implicado un proceso social y de aprendizaje significativo que le ha entregado valores, herramientas operativas y también habilidades blandas, todas ellas útiles tanto para sus procesos de aprendizaje escolar como para su futura inserción social fuera del medio escolar, como también en futuras etapas formativas post-secundarias.

b) Desde el punto de los valores, todos aquellos que son destacados y relevados por los propios estudiantes son plenamente coincidentes tantos con el ideario de principios y valores del modelo cooperativo clásico, pero que también tienen una relación directa con los marcos de participación social y cívica de todo ciudadano en una democracia moderna, por lo que permiten vislumbrar una sinergia positiva entre ambas dimensiones.

c) En relación a las aptitudes desarrolladas al interior de la cooperativa en base a la participación de los estudiantes, que podemos relacionar directamente con lo que se conoce como competencias blandas o transversales, tales como trabajo en equipo, comunicación, constancia y perseverancia, autocontrol, entre otras, vemos que todas ellas son de gran utilidad en cualquier escenario social, educativo o laboral futuro que los jóvenes puedan enfrentar, por lo que se presenta la oportunidad de participar activamente en el espacio de la cooperativa escolar como un ambiente enriquecedor y que propende al desarrollo personal.

d) Finalmente cabe destacar en lo que dice relación a habilidades específicas de gestión de empresas y organizaciones, temas como contabilidad, derecho, contabilidad, artes, etc., evidentemente se pueden destacar como parte de un proceso creciente de desarrollo de capacidades que en el marco general de las habilidades emprendedoras podrán ser puestas en práctica en múltiples escenarios futuros.

\subsection{Recomendaciones vinculadas a profundización de líneas de investigación y políticas públicas}

a) Se ve del todo recomendable que los poderes públicos en el ámbito educativo, pero también del emprendimiento y desarrollo productivo, tal como ya sucede en diversos países, pongan mayor atención en promover programas públicos de apoyo al emprendimiento social y cooperativo en todos los niveles educativos desde el nivel infantil a la educación superior. La dimensión propiamente curricular aquí es fundamental.

b) Particular atención hay que poner en la formación inicial y continua del personal docente en los establecimientos académicos, pues son ellos los responsables directos de interactuar cotidianamente con los estudiantes. Su formación y perfeccionamiento en la temática general de emprendimiento y, en específico, de emprendimiento social cooperativo se presentan como un factor "crítico" de éxito en este tipo de iniciativas.

c) Promover la sistematización de buenas prácticas y la realización de programas de intercambio y pasantía entre estudiantes, directivos, profesores y personal administrativo, aparece como un factor clave para promover y difundir este tipo de iniciativas.

d) Finalmente existe un área fundamental de investigación que dice relación con el impacto en los procesos de aprendizaje general de los estudiantes que han participado en experiencias de cooperativas escolares. Una hipótesis es que esta participación debiera tener un impacto positivo en los aprendizajes de las asignaturas regulares como también en su comportamiento tanto al interior del establecimiento como fuera de él. Una hipótesis que sería de total valor poder explorar.

\section{Referencias bibliográfícas}

Ahumada, F. (2017) Estudio del Modelo de Gestión Participativa en las Cooperativas Escolares. Trabajo para obtener el título de Ingeniero Civil Industrial. Universidad de Santiago de Chile, Facultad de Ingeniería, Departamento de Ingeniería Industrial.

Amorós, J. y Acha, A. (2014) Reporte Nacional de Chile 2013. Global Entrepreneurship Monitor, 88.

Comisión Europea, Dirección General de Empresa (2002) Informe Final del Grupo de Expertos. Proyecto del Procedimiento Best sobre Educación y Formación en el Espíritu Emprendedor. Comisión Europea, Bruselas.

Consejo Nacional de Innovación para la Competitividad (2008) Informe de resultados estadísticas básicas e índices preliminares.

Coperativas de las Américas (2017) Cooperativas escolares.

Corporación de Fomento de la Producción - CORFO (2013) Línea Base Gestión de la Innovación en el Sector Público.

Cruz-Coke, R. (2006) Evolución de las universidades chilenas 1981-2004. Rev. Méd. Chile 2004, № 132, pp. 15431549. ISSN 0034-9887: https://bit.ly/2UacGoP.

Diario Oficial de la República de Chile (2003) Ley 19.832. Santiago, Chile: https://bit.ly/2BT59DS.

English, J. (2012) Trabajadores aún prefieren ser dependientes antes que emprendedores. Recuperado el domingo 23 de Diciembre de 2017. Diario La Tercera: https://bit.ly/2EzaEcs. 
Fernández Guadaño, J. F. (2000) La realidad actual de las sociedades cooperativas en la educación. REVESCO. Revista de Estudios Cooperativos, $\mathrm{N}^{\mathrm{o}}$ 71, pp. 55-76. ISSN 1135-6618.

Fernández Guadaño, J. (2003) La participación, factor determinante de la calidad educativa de los centros docentes cooperativos. REVESCO. Revista de Estudios Cooperativos, № 79, pp. 35-58.

France Diplomatie, (2014) La educación, elemento esencial del desarrollo sostenible. https://bit.ly/2GMBvnT.

Galdos de Isusi, M. (2013) Adolescencia y amistad. Madrid, España.: https://bit.ly/1TQ4RfA.

Global Entrepreneurship Monitor (2012) Global Report 2012. https://bit.ly/1Lge4OP.

Global Entrepreneurship Monitor (2015) Reporte Nacional de Chile 2014. Universidad del Desarrollo, Santiago de Chile. https://bit.ly/1Lge4OP.

Goleman, D. (1995) Inteligencia Emocional. https://bit.ly/2U9Eo53.

Gui, B. (1991) Los papeles beneficiarios y dominantes en las organizaciones: el caso de las no lucrativas. Cuadernos de Trabajo, No 10, CIRIEC-España.

Hernández, R., Fernández, C. y Baptista, P. (2003) Metodología de la Investigación. México, D. F., México: McGrawHill Interamericana. Recuperado el 2016.: https://bit.ly/2tHTRxM.

Inglada Galiana, E., Sastre Centeno, J. M., y Villaroya Lequericaonandia, B. (2015) El cooperativismo en la educación. REVESCO. Revista de Estudios Cooperativos, Segundo Cuatrimestre, № 118, pp. 122-147. ISSN: 1135-6618. DOI: 10.5209/rev_REVE.2015.n118.49059.

Levin, A. (2015) Teoría e Historia de la Economía Social. https://bit.ly/2GPE08L.

Levesque, B. (2002) Entrepreneurship collectif et économie sociale: entreprende autrement. https://bit.ly/2NwdNNa.

Mancilla, A. (2005) Antecedentes para una historia de la educación primaria en Chile. Siglos XIX y comienzos del XX. Tesis para optar al grado de Magíster en Historia. Universidad de Chile.

Martín López, S.; Fernández Guadaño, J.; Bel Durán, P. y Lejarriaga Pérez de las Vacas, G. (2013) Necesidad de medidas para impulsar la creación de las empresas de participación desde los diferentes niveles de enseñanza. CIRIEC-España. Revista de Economía Pública, Social y Cooperativa, No 78, pp. 71-100. ISSN 0213-8093.

Martínez, M. (2001) La confianza en Chile. Antecedentes y desafíos para una cultura democrática. Santiago, Chile. ISSN 0718-2236. http://dx.doi.org/10.4067/S0718-22362011000100008.

Ministerio de Economía, Fomento y Turismo, (2014) El Cooperativismo en Chile. Unidad de Estudios. Recuperado el 2016. Extraído de: https://bit.ly/2H6xzgV.

Morales Gutiérrez, A. y Ariza Montes, J. (2013) Valores, actitudes y motivaciones en la juventud ante el emprendimiento individual y colectivo. REVESCO. Revista de Estudios Cooperativos, $\mathrm{N}^{\circ}$ 112, pp. 11-35. ISSN 1135-6618.

Moreno Hernández, R. (2000) Realidad actual y perspectivas de futuro para las sociedades cooperativas en la educación. REVESCO. Revista de Estudios Cooperativos, No 71, pp. 83-91.

Navarro, A. y Campos, V. (2009) Emprendedurismo y economía social como mecanismos de inserción sociolaboral en tiempos de crisis. España. ISSN: 1885-8031: https://bit.ly/2TfDgjl.

OCDE (2014) Informe Ocde: Chile se ubica entre los países con la educación superior más costosa. Recuperado el 2016: https://bit.ly/2EDutjb.

ONU: Asamblea General (1948) Declaración Universal de Derechos Humanos. https://bit.ly/2TinX9v.

Pérez, E. (2013) Competencia de interacción con el alcohol en adolescentes: Efectos de una e-intervención. Universidad de Almería: https://bit.ly/2T0roSO.

Publimetro, (2013) Educación superior chilena, la más cara del mundo: OCDE: https://bit.ly/2TfDozl.

Radrigán, M., Dávila, A. y Penaglia, F. (2012) Emprendimientos sociales y liderazgo en el sector no lucrativo chileno. Modelos de gestión y buenas prácticas, $\mathrm{N}^{\mathrm{o}}$ 2, pp. 1-26.

Radrigán, M. (2007) Procesos educativos, juventud y desarrollo de la capacidad emprendedora asociativa. Lecciones del análisis de experiencias internacionales. GEZKI. Recuperado en Septiembre de 2016. 1-26

Real Academia Española. (2014) Diccionario de la lengua española. Madrid, España: https://bit.ly/2Nwzn4e.

Redondo, J. (2015) La extinción de la educación pública en Chile. Buenos Aires, Argentina, CLACSO.

Reyes, J. y Quijano, J. (2004) Historia y doctrina de la cooperación. Bogotá: Universidad Cooperativa de Colombia. Recuperado el 2016: https://bit.ly/2VpcuCe.

Rodríguez, C. (2004) Trabajo Juvenil y Construcción de Protagonismo Social: el caso de las cooperativas escolares. Análisis de los Discursos Juveniles en torno a Experiencias de Trabajo y Protagonismo Social desde la Participación en Cooperativas Escolares. Memoria para optar al título de Socióloga. Universidad de Chile, Facultad de Ciencias Sociales, Departamento de Sociología.

UNICEF, (2011) Estado Mundial de la Infancia 2011. Recuperado en diciembre de 2016: https://uni.cf/2XBnWgi.

Universitat Politècnica de València (s.f.) Inteligencia Emocional. https://bit.ly/2s0Aj6t.

Urrecoa, J. (s/f) Reflexiones: Peter Cornelius Plockboy y la República Cooperativa. https://bit.ly/2TkkEOV.

Vassilou, A. (2012) La educación para el emprendimiento se abre paso. Recuperado el 13 de Abril de 2012 : https://bit.ly/2UaUZWp.

Valdez, J., Mondragón, J., González, N., López, A., y González, S. (2004) Significado Psicológico de "Respeto" entre Adolescentes. Toluca, México: Universidad Autónoma de México. Revista Internacional de Ciencias Sociales y Humanidades, SOCIOTAM, XIV (1), 113-129. ISSN: 1405-3543: https://bit.ly/2tHy75e.

Valdebenito, M. (2013) Habilidades Blandas, fundamentales para el desarrollo personal. (M. Silva, Entrevistador): https://bit.ly/2CEisYa. 